Spotlight on the October 30 Issue

\author{
Robert A. Gross, MD, PhD, FAAN
}

Editor-in-Chief, Neurology ${ }^{\circledR}$

Hormone therapy and Alzheimer disease dementia: New findings from the Cache County Study $\mathbb{E}]$

This study followed 1,768 women who used hormone therapy, with 176 developing incident Alzheimer disease. Hormone therapies are associated with a reduced risk of subsequent Alzheimer dementia if taken during a critical window near menopause, but may be associated with an increased risk if initiated later in life.

See p. 1846; Editorial, p. 1840

Upper limb ischemic preconditioning prevents recurrent stroke in intracranial arterial stenosis :

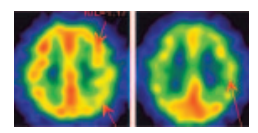
The authors evaluated protective effects of brief repetitive bilateral arm ischemic preconditioning on stroke recurrence in 68 patients with symptomatic atherosclerotic intracranial arterial stenosis. This noninvasive strategy has promise as a stroke preventive.

See p. 1853; Editorial, p. 1842

\section{Selective serotonin reuptake inhibitors and brain} hemorrhage: A meta-analysis

The authors performed a systematic review and metaanalysis of 16 epidemiologic studies on the association of selective serotonin reuptake inhibitors and CNS hemorrhage. Likelihood of intracranial and intracerebral hemorrhage was higher in patients exposed to these agents, but the absolute magnitude of risk for most patients is likely to be very low. See p. 1862

From editorialists McGrath \& O'Donnell: “These findings add to the totality of evidence for efficacy and safety of antidepressants overall and within drug classes, used to inform evidence-based prescribing."

See p. 1844

Neurologic disorders incidence in HIV+ vs HIV- men: Multicenter AIDS Cohort Study, 1996-2011

The authors compared the incidence and pattern of neurologic disorders in HIV-positive men, compared to HIV-negative men, in the era of highly active antiretroviral therapy (HAART). There were 3,945 participants $(2,083 \mathrm{HIV}$ negative, $1,776 \mathrm{HIV}$ positive, and 86 who became infected with HIV during the study period). Neurologic diagnoses were higher in HAART-treated HIV-positive versus HIV-negative participants.

See p. 1873

\begin{abstract}
Migraine and migraine subtypes in preadolescent children: Association with school performance $P$ t

School performance was determined by directly interviewing teachers about competencies in language, mathematics, science, and social studies in children from 87 cities and 18 Brazilian states. Children with migraine were at an increased risk of having impairments in their school performance relative to children without headaches.

See p. 1881
\end{abstract}

Burden of uncontrolled epilepsy in patients requiring an emergency room visit or hospitalization

Health insurance claims from a 5-state Medicaid database and 55 self-insured US companies from patients with epilepsy receiving antiepileptic drugs were analyzed. Uncontrolled epilepsy in patients requiring emergency room visits or hospitalizations was associated with greater health care resource utilization and increased costs compared to well-controlled epilepsy in publicly and privately insured settings.

See p. 1908

VIEWS \& REVIEWS

Moving toward molecular classification of diffuse gliomas in adults

A classification scheme was proposed separating diffuse gliomas, grades II to IV, into prognostic groups based on their molecular profile. Improving classification and prognostication is a necessary step toward developing personalized therapy for glioma patients.

See p. 1917

NB: Resident \& Fellow Media and Book Reviews, see p. e164. To check out other Resident \& Fellow submissions, point your browser to www.neurology.org and click on the link to the Resident \& Fellow Section.

Podcasts can be accessed at www.neurology.org 


\title{
Neurology
}

\author{
Spotlight on the October 30 Issue \\ Robert A. Gross \\ Neurology 2012;79;1839
}

DOI 10.1212/WNL.0b013e318274271d

This information is current as of October 29, 2012

\section{Updated Information \&}

Services

Permissions \& Licensing

Reprints including high resolution figures, can be found at: http://n.neurology.org/content/79/18/1839.full

Information about reproducing this article in parts (figures,tables) or in its entirety can be found online at:

http://www.neurology.org/about/about_the_journal\#permissions

Information about ordering reprints can be found online:

http://n.neurology.org/subscribers/advertise

Neurology ${ }^{\circledR}$ is the official journal of the American Academy of Neurology. Published continuously since 1951, it is now a weekly with 48 issues per year. Copyright Copyright $@ 2012$ by AAN Enterprises, Inc.. All rights reserved. Print ISSN: 0028-3878. Online ISSN: 1526-632X.

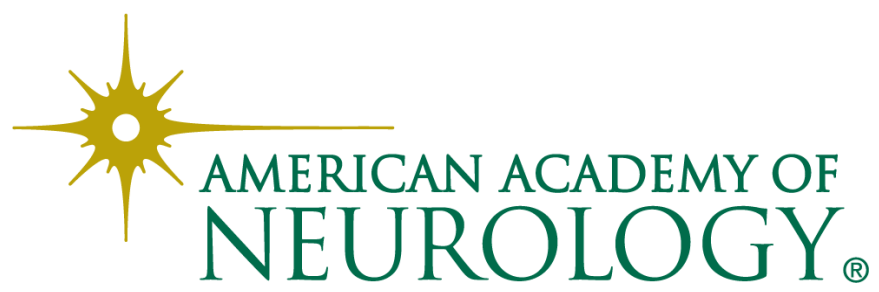

